\title{
Research on the Coordinated Development of Global Urban Economic Competitiveness: Based on a Sample of 1007 Cities
}

\author{
Xiaonan Liu, ${ }^{1,2}$ Pengfei Ni, ${ }^{3}$ Fangqu Niu $\mathbb{D}^{4},{ }^{4} \mathrm{Bo} \mathrm{Li},{ }^{5}$ and Qihang $\mathrm{Li}^{6}$ \\ ${ }^{1}$ Tehua Postdoctoral Programme, Beijing 100029, China \\ ${ }^{2}$ Institute of Finance \& Banking, CASS, Beijing 100710, China \\ ${ }^{3}$ National Academy of Economic Strategy, CASS, Beijing 100006, China \\ ${ }^{4}$ Institute of Geographic Sciences and Natural Resources Research, CAS, Beijing 100101, China \\ ${ }^{5}$ School of Management, Tianjin University of Technology, Tianjin 300384, China \\ ${ }^{6}$ Economic Research Center, Shandong University of Finance and Economics, Jinan 250014, China \\ Correspondence should be addressed to Fangqu Niu; niufq@lreis.ac.cn
}

Received 28 July 2021; Revised 29 September 2021; Accepted 13 November 2021; Published 7 December 2021

Academic Editor: Jing-Hu Pan

Copyright ( $\odot 2021$ Xiaonan Liu et al. This is an open access article distributed under the Creative Commons Attribution License, which permits unrestricted use, distribution, and reproduction in any medium, provided the original work is properly cited.

Based on the global urban economic competitiveness data in 2017, this study conducts coupling analyses of the competitiveness indicator system. The comprehensive study on the coupling coordination degree among explanatory indexes of urban economic competitiveness concludes that the city with higher economic competitiveness rankings has a higher degree of coupling coordination (DCC); the city ranked lower in the economic competitiveness has a lower DCC. The cities with higher DCC are mainly those global cities or metropolis known for financial and technological innovations, while cities with bare coupling coordination are mainly in underdeveloped countries in Asia, Africa, and Latin America. Based on the findings, the paper employs a model that combines linear regression and quantile regression to identify the specific driving factors that affect the cities' competitiveness around the world. Therefore, every city should act according to local conditions, focus on the key drivers of urban development, and address the inadequacies to balance the economic development so as to enhance its competitiveness.

\section{Proposition and Literature Review}

1.1. Proposition. As urban population continues to grow after entering the new century, urban competitiveness is becoming more and more prominent in the development of human society. The improved transportation and advanced Internet and other information technologies have greatly shortened the distance between people and facilitated the interactions between cities with growing mutual influences. This has also aggravated the competitions for resources and businesses among the cities. With deepening economic globalization, the lagging development of developed economies, and the rapid rise of emerging economies, cities around the world face more opportunities and challenges. As the competition among cities is increasingly intensified, urban competitiveness has become a key issue concerning how a country or a region can survive and develop under the pressure of global competition. The World Economic Forum continues to foster international exchanges and cooperation to address the issue. Urban competitiveness, as a topic of scientific researches, has caused widespread concerns among experts and scholars in various disciplines, including economy, geography, and urban planning, and has become a major national policy agenda.

On the other hand, there is a wooden barrel effect in the actual economic and social development. It is very important to study whether there is a barrel effect in urban competitiveness and promotion strategies. According to the "Global Urban Competitiveness Report 2017-2018” jointly published by the Chinese Academy of Social Sciences and UNHABITAT, the top ten cities in the global competitiveness are cities in developed countries, except Shenzhen in China. Over half of these cities are in the United States. The global economic competitiveness is highly concentrated in a few 
cities, a seriously unbalanced development among the cities worldwide. Cities in developed countries such as the United States, Germany, and the United Kingdom generally have relatively strong economic competitiveness, while cities in developing countries such as China and India make up a center-periphery pattern, in which the center cities have much stronger competitiveness than other cities in the country. To focus on priorities, address inadequacies, and shore up points of weakness are currently important starting points to enhance the urban economic competitiveness.

The DCC is to measure the synergy between systems and analyze the degree of coordinated development of systems. Therefore, the coupling coordination degree model can not only reflect the degree of interaction between systems, but also reflect the level of coordinated development of systems. In studying competitiveness, to analyze and compare the DCC in the urban competitiveness is very important for the cities to enhance their respective competitiveness. Such studies shed light on the future development and deepen the understanding of each city's specific internal structure and competitiveness. By analyzing the relative indexes of economic competitiveness, such as technology innovation, financial services, industrial systems, human resources, business environment, business cost, infrastructure, and living standards, the factors that are staying in line with, moving ahead of, or lagging behind the development of economic competitiveness can be identified. By addressing the key factors that restrict the DCC in city's competitiveness, adjusting the measures to suit local conditions, and concentrating on the factors that can significantly boost competitiveness, including technology, finance, local demand, business environment, and infrastructure, the economic competitiveness of cities around the world can be enhanced.

This study is intended to analyze the DCC and urban competitiveness of cities across the world and examines the influencing factors of urban competitiveness, which have not been fully and accurately analyzed due to the limitations of data collection and statistical range. Therefore, this paper fills in the research gap on global urban competitiveness and provides reference points in improving the economic competitiveness of global cities.

1.2. Literature Review. Coupling coordination theory was first proposed by Haken, a German physicist, in the 1970s [1]. It was originally used in the field of laser physics. Prior to this, in the 1930s, the Austrian-American biologist Bertalanffy first proposed the general system theory in the field of biology [2]. The theory of coupling coordination was developed by later generations and consistently applied in the field of economics [3-6]. There are few literatures on the DCC, and there are even fewer studies on coupling coordination between the various indicators of urban competitiveness and the cities' competitiveness. So far, there is no study on the DCC between various urban factors, which has important significance to the analysis and studies on the DCC between cities. This study, based on 1,007 sample cities, constructs a global competitiveness indicator system that comprises 10 Level-2 indicators and 24 Level-3 indicators to analyze the coupling coordination between economic competitiveness and the explanatory indicators, such as technological innovation, financial services, industrial systems, business environment, operational cost, and living standards. The derived DCC are classified into four tiers, to which the sample cities are assigned accordingly. This model shows the distribution of these cities' DCC and indicates a strong correlation to the urban competitiveness. The following analysis will be focused on the coupling degrees between the factors of urban competitiveness and the characteristics of economic competitiveness itself.

The multidimensional nature of urban competitiveness is the premise and basis for a possible coupling analysis. Most scholars emphasize that the factors affecting urban competitiveness are complex and multidimensional, different from the single factor for business competitiveness, the economic performance [7-11]. Lever $(1993,1999,2002)$ believes that what makes a successful city should be a combination of economic development, sustainability, and quality of life [12-14]. Cities should pay more attention to "soft" assets such as innovation environment, corporate relations, resident's expectation, institutional capacity, and quality of education and research. He also points out that the supporting elements for successful competition are a series of multidimensional factors, including aspiring and peopleoriented leadership; flexible and adaptive workforce; quick and responsive public administration; efficient corporate partnerships; and entrepreneurial environments. The Beacon Hill Institute has been evaluating the long-term competitiveness of each state of the United States since 2001 $[15,16]$. In his study, the long-term competitiveness is attributed to eight factors: local government and taxation policies, security, infrastructure, human resources, technology, business incubation, inclusiveness, and environmental policy.

Kresl and others believe that regional competitiveness has a self-enhancement (inner coupling) mechanism [17-20]. This mechanism is first reflected in the fundamental aspects of the region (education, corporate culture, public infrastructure and services, institutional composition and trends, policy regime, and cultural atmosphere) and the external economic engagement in the region (specialized labor pool, specialized supply and service network, knowledge dissemination and technology transfer, specialized systems, and dedicated capital markets; the second is the regional competitiveness (innovation, investment, technology, business, networks, diversified and specialized economy, quality of life, and strategic policies). The third is output, that is, the external characteristics of competitiveness (productivity, employment, wages, and per capita GDP). The input and direct contribution of the output also become part of the driving force, which, in turn, contributes to the output; and then the output also reacts with the input and the impetus $[21,22]$. This circular and accumulated selfenhancement process constitutes the coupling characteristic of the multidimensional indicators of the urban competitiveness. The pyramid model of urban competitiveness proposed by Begg (1999) also embodies the coupling 
characteristics [23]. This model is composed of four levels. The bottom level is the various environmental factors that affect urban competitiveness, including the top-down institutional and macro environment, company characteristics, business environment, innovation, and learning capacity. In this regional competitiveness assessment model, labor productivity and employment rate are regarded as dominant factors of urban competitiveness. Other environmental factors are explanatory factors.

Hao and Ni $(1998,2001)$ established a "Bow-StringArrow-Target" model of urban competitiveness [24, 25]. The bow and string represent the hard and soft elements of competitiveness, while the arrow represents the competitive industry, the value of competitiveness. This objectively requires that a city has bow and string (hard factor and soft environment, input) to determine the arrow (industry, process) and then to form a multielement coupling system with decisive (value, economic output) and reciprocal feedbacks from opposite directions. At the same time, the coupling competitiveness also comes from common changes beyond the economic indicators. Ivan and Turok (2004) believe that competitiveness can be measured by the economic growth in foreign investment, the existing local businesses, and the start-ups [26]. The single index such as the gross added value of per capita GDP and per worker GDP is most commonly used to rank the overall economic growth and productivity. However, more complex measurements such as fairness, distribution efficiency, and indicators of sustainable economic growth should be included, because local governments usually adopt competition strategies that only hold on to labor costs and direct taxing that sacrifices the environment and cuts welfare $[27,28]$. Bruneckiene et al. (2010) believe that the current elements of urban competitiveness are used as input to create future factor output, which then becomes an input in the cyclical process that forms new urban competitiveness. Of course, the whole process can also be run in reverse direction and is a continuous and circular cycle in improving urban competitiveness [29]. The strategic decisions are based on the latest measurement results of a city's competitiveness and potential. In other words, there is a correlation between the urban competitiveness in the economic sense and the urban competitiveness in the noneconomic sense. To coordinate and promote development and to promote coordination through development are a collective expression of the multidimensional and multifaceted urban competitiveness [30-33].

$\mathrm{Ni}(2006,2017)$ defines the urban competitiveness as a city's capacity to attract, compete for, own, control, and transform resources, and to compete for, to seize, and to control markets, to create value so as to benefit its people, in comparison to other cities in the course of competition and development $[34,35]$. Based on the model to measure a country's competitiveness developed by Porter et al. [36, 37], $\mathrm{Ni}$ et al. (2015) establish a model to study the factors of urban competitiveness [38]. Their model includes six latent variables: $\mathrm{UC}=f(\mathrm{EQ}, \mathrm{LE}, \mathrm{LD}, \mathrm{LC}, \mathrm{GC}, \mathrm{SE}, \mathrm{HE})$. Among them, UC represents the input of urban competitiveness. EQ refers to the quality of the business entity; LE refers to the main supply of local factors; LD is the demand of the local market; LC reflects the internal networking and aggregation of the city; GC represents the city's external connection via external factors and markets; SE and HE, on the other hand, represent the institutional rules, environment and the local infrastructure, and environments that interact with the subject. In addition, the study of $\mathrm{Ni}$ et al. also uses quantitative methods to measure the competitiveness index of 500 cities around the world and divide these cities into 7 distinct categories by applying dynamic clustering analysis; with stepwise regression analysis, their study finds that different types of cities have different determinants of competitiveness: technological innovation, global connections, and international brands are the determinants to become the world's top cities; the business and living environment and the size of the population are the determinants for the fast growing emerging central cities; for the less developed cities, the determinants are infrastructure, wages, and living standards. Therefore, different strategies and measures should be adopted to enhance urban competitiveness.

\section{Data and Research Methods}

2.1. Indicator System of Urban Competitiveness. A sample of 1007 cities with a population of 500,000 or more across the world are selected based on the " 2015 World Urbanization Prospects" issued by the UN Department of Economic and Social Affairs. These sample cities are distributed in 136 countries or regions in 6 continents. Among them, there are $566,126,131,102,75$, and 7 in Asia, Europe, North America, Africa, South America, and Oceania, respectively. The reason for the selection of these cities is that they are very representative in terms of city sizes, the level of development, spatial distribution, etc.

Urban competitiveness is fundamentally a regional competitiveness. According to the theoretical framework, in terms of output, performance, and interpretation, urban competitiveness is a city within its spatial scope to create value and obtain the scale, level, and growth of economic rent. According to the principle of minimization of indexes, economic density (GDP per land area) is the proper indicator of the efficiency and level of value creation, while economic growth (the difference between GDP of the current year and GDP of the previous year) is an indicator of the scale and growth rate of value creation. These two indicators can be combined as an index to better reflect the explanatory variables of economic competitiveness and to express the overall long-term growth and the overall economic efficiency of the urban economy. To measure by using five consecutive years of average GDP growth and GDP density, we establish the model for urban economic competitiveness as follows: 


$$
\begin{aligned}
\mathrm{GUCI}_{i}= & \left(\frac{\left(\mathrm{GDP}_{i} / \mathrm{IDEA}_{i}\right)-\left(\overline{\mathrm{GDP}_{i}} / \mathrm{IDEA}_{i}\right)}{\partial^{2}}\right) \times\left(\frac{\left(\mathrm{GDP}_{i} / \mathrm{POP}_{i}\right)-\left(\overline{\mathrm{GDP}_{i}} / \mathrm{POP}_{i}\right)}{\partial^{2}}\right) \\
& +\left(\frac{\left(\mathrm{GDP}_{i}^{t} / \mathrm{GDP}_{i}^{t-1}\right)-\left(\overline{\mathrm{GDP}_{i}^{t}} / \mathrm{GDP}_{i}^{t-1}\right)}{\theta^{2}}\right),
\end{aligned}
$$

where $\mathrm{GUCI}_{i}$ represents the index of the global urban competitiveness of city $i$.

The left side of the plus sign in formula (1) is the standardized economic density index of city $i$ after being adjusted with per capita GDP.

$\left(\left(\mathrm{GDP}_{i}^{t} / \mathrm{GDP}_{\mathrm{i}}^{t-1}\right)-\left(\overline{\mathrm{GDP}_{i}^{t}} / \mathrm{GDP}_{\mathrm{i}}^{t-1}\right) / \theta^{2}\right)$ is a standardized index of economic growth of the city $i$, which uses the average growth of 5 executive years of GDP to measure the comprehensive long-term growth. According to the theoretical framework, the relationship between competitive input and process and competitiveness should be the relationship between the explanatory variables and the explained variables interpretation. By making reference to the macroeconomic cycle theory and Michael Porter's competitive advantage theory, the model of the factors affecting competitiveness is as follows:

$$
\mathrm{EEC}=F(\mathrm{FE}, \mathrm{TI}, \mathrm{IS}, \mathrm{HR}, \mathrm{LD}, \mathrm{CC}, \mathrm{SE}, \mathrm{IN}, \mathrm{LE}) .
$$

The input of urban competitiveness refers to the factors and environments of the city, including financial services, technological innovation, industrial system, human capital, local demand, business costs, institutional costs, infrastructure, living cost, and global connections. The output of all factors ultimately manifests itself as the city's competitiveness. Based on the above theoretical analysis, this paper constructs the following explanatory model of economic competitiveness:

Economic Competitiveness (EEC) is the explained variable; it is also called explicit variable. All variables in parentheses on the right side of formula (2) are explanatory variables, including Industrial System (IS), Technology Innovation (TI), Financial Services (FE), Human Resources (HR), Local Demand (LD), Corporate Cost (CC), System Environment (SE), Infrastructure (IN), and Living Environment (LE). All the data comes from the database of the Chinese Academy of Social Sciences City and Competitiveness Index. It should be pointed out that these indicators are compound indicators comprised of a number of specific indicators. See Table 1 for the specific indicator system.

2.2. Measurements. This section mainly introduces the degree of coupling and coordination among multiple variables.

Multivariable Coupling Coordination is as follows:

$$
\begin{aligned}
\mathrm{DC}_{m} & =\left\{\frac{\prod_{i=1}^{n} g_{i}(x)}{\left[\prod_{i=1, i<j}^{n}\left(\left(g_{i}(x)+g_{j}(x)\right) / 2\right)\right]^{2 / n}}\right\}^{1 / n}, \\
T & =\sum_{i=1}^{n} \lambda_{i} g_{i}(x), \\
\text { DCCI } & =\sqrt{\mathrm{DC}_{m} * T} .
\end{aligned}
$$

In formulas (3) to (5), where $g_{i}(x)$ represents the value of the $i$ variable of a city, $\mathrm{DC}_{\mathrm{m}}$ is the degree of coordination between $n$ variables in a city, $\lambda_{i}$ is the weight given to the $i$ variable in the evaluation system, and DCCI is the degree of coupling and coordination between $n$ variables in a city; that is to say, it is the DCC between $n$ variables.

Coupling degree only reflects the degree of coordination between systems or elements, It focuses on emphasizing coordination, failure to reflect the interactive development of each other. Sometimes, there could be pseudocoordination, that is, coordination under a low level of development. Coupling degree and DCC are two different concepts. The degree of coupling and coordination emphasizes overall coordinated development, learning from each other's strengths, and avoiding shortcomings. High coupling degree between variables does not necessarily imply strong coupling coordination, because the coupling might occur with low coordination; however, the high DCC indicates higher coupling degree between systems, because it gives the weighted coefficient between the systems. The levels and categories of DCC are shown in Table 2 .

How extensive and representative the samples are accounts for the accuracy and value of the study. This paper selects a sample of cities with a population of more than 500,000 across the world from the "2015 World Urbanization Prospects" issued by the UN Department of Economic and Social Affairs. Combined with China's urban context, a total of 1007 sample cities are selected from the global community. In terms of the spatial distribution, these 1,007 sample cities are distributed in 6 continents and 136 countries or regions; among them, 566 are in Asia, 126 in Europe, 131 in North America, 102 in Africa, 75 in South America, and 7 Oceania cities. They basically represent the different urban development in different regions around the world today. It should be noted that this article uses the metropolitan area (MSA) caliber. The data are drawn from the City and Competitiveness Index database of the Chinese Academy of Social Sciences. 
TABLE 1: Explanatory indicators of the economic competitiveness of cities across the globe.

\begin{tabular}{|c|c|c|c|}
\hline Categories of indicators & Indicators & Categories of indicators & Indicators \\
\hline Financial services (FE) & $\begin{array}{c}\text { Bank index } \\
\text { Bank branches index } \\
\text { Exchange index }\end{array}$ & Operation cost (CC) & $\begin{array}{c}\text { Loan interest rate } \\
\text { Tax to GDP ratio } \\
\text { Per capita income/benchmark price }\end{array}$ \\
\hline $\begin{array}{l}\text { Technology innovation } \\
\text { (TI) }\end{array}$ & $\begin{array}{c}\text { Patent index } \\
\text { Research paper index } \\
\end{array}$ & $\begin{array}{l}\text { System environment } \\
(\mathrm{SE})\end{array}$ & $\begin{array}{c}\text { Convenience of doing business } \\
\text { Level of economic freedom }\end{array}$ \\
\hline Industry system (IS) & $\begin{array}{l}\text { Production services business } \\
\quad \text { index } \\
\text { Technology enterprise index }\end{array}$ & Infrastructure (IN) & $\begin{array}{c}\text { Convenience of transportation } \\
\text { Broadband users }\end{array}$ \\
\hline Human resources (HR) & $\begin{array}{l}\text { Workforce population }(15-59) \\
\text { The proportion of youth } \\
\text { population } \\
\text { College index }\end{array}$ & $\begin{array}{l}\text { Living environment } \\
\text { (LE) }\end{array}$ & $\begin{array}{l}\text { The logarithm of the number of airlines and airport } \\
\text { distance } \\
\text { PM } 2.5 \\
\text { Crime rate }\end{array}$ \\
\hline Local demand (LD) & Total disposable income & & \\
\hline
\end{tabular}

TABLE 2: The levels and categories of DCC.

\begin{tabular}{lcccc}
\hline \multicolumn{4}{c}{ Levels and categories of DCC } \\
\hline Coordination degrees & $0-0.5$ & $0.5-0.6$ & $0.6-0.8$ & $0.8-1$ \\
Coordination categories & Scant coordination & Limited coordination & Good coordination & Strong coordination \\
Coordination levels & 4 & 3 & 2 & 1 \\
\hline
\end{tabular}

\section{Empirical Analysis}

The empirical study first examines the DCC of cities around the world and then presents its spatial distribution and hierarchical structure. In the end, regression analysis is used to verify the impact of coupling coordination on urban competitiveness.

\subsection{The Coupling Coordination of Cities Worldwide.} Figure 1 is a kernel density graph of the DCC of cities across the world. It shows the distribution characteristics. Compared to a standard normal distribution, this pattern is a bit to the left. Such a distribution suggests that the DCC differ greatly with only a few cities reaching a high level, while many others have lower DCC and need improvement. Specifically, the global average DCC is 0.481 , the median 0.515 , the variance 0.0395 , and the coefficient of variation $0.391 ; 37.94 \%$ of the cities are below average; those above average concentrate in a few developed countries. Currently, New York City of the United States has the highest DCC. Among the top 20 cities, seven are in the United States, three in China, two in Japan, and Australia, Germany, Russia, France, South Korea, Canada, Singapore, and the United Kingdom each have one city among them, indicating a notable imbalance in the distribution.

Figure 2 is a scatter plot of the DCC and economic competitiveness of cities around the world. It shows the correlation between the two. Cities ranked in the middle range by competitiveness have DCC between 0.4 and 0.6 ; the correlation coefficient between these cities' economic competitiveness and the DCC is 0.69 , indicating very strong correlation between the two. There is a strong correlation between the degree of urban economic competitiveness and the DCC; i.e., cities with higher economic competitiveness rankings show higher DCC between the overall explanatory indicators and economic competitiveness, while cities ranked lower by economic competitiveness have lower DCC between overall explanatory indicators and economic competitiveness.

3.2. Spatial Distribution of the DCC of Cities across the World. In order to facilitate the analysis of the spatial distribution of the DCC of cities across the world, we categorize the 1,007 sample cities into four tiers: tier 1 includes cities of excellent coordination with coupling degrees between 0.8 and 1 ; tier 2 includes cities of good coordination with coupling degrees between 0.6 and 0.8 ; tier 3 covers cities of slight coordination with coupling degrees between 0.5 and 0.6 ; and tier 4 covers cities of coupling coordination in barely balanced condition with coupling degree at 0.5 or under. We use bubble chart to visualize the coupling coordination of the 1007 sample cities in this paper. Figure 3 shows the distribution of the coupling coordination of these cities.

The spatial distribution of the DCC shows that cities with excellent or good DCC account for less than a quarter of the 1,007 sample cities and that cities with DCC representing bare balance or severe imbalance account for $2 / 7$ and $3 / 7$ of the 1,007 sample cities, respectively. By continent, nearly 92\% of the first two tiers are cities in Europe, North America, and Asia, with the three continents, respectively, accounting for $27.24 \%, 31.34 \%$, and $32.84 \%$ of the total, while up to $86.33 \%$ of the latter two tiers are cities in Asia, Africa, and South America, of which cities in Central Asia, Africa, and South America account for about three-quarters of the total. Asian cities see larger gaps in their DCC. Developed cities in Europe, North America, and Asia have higher DCC, 

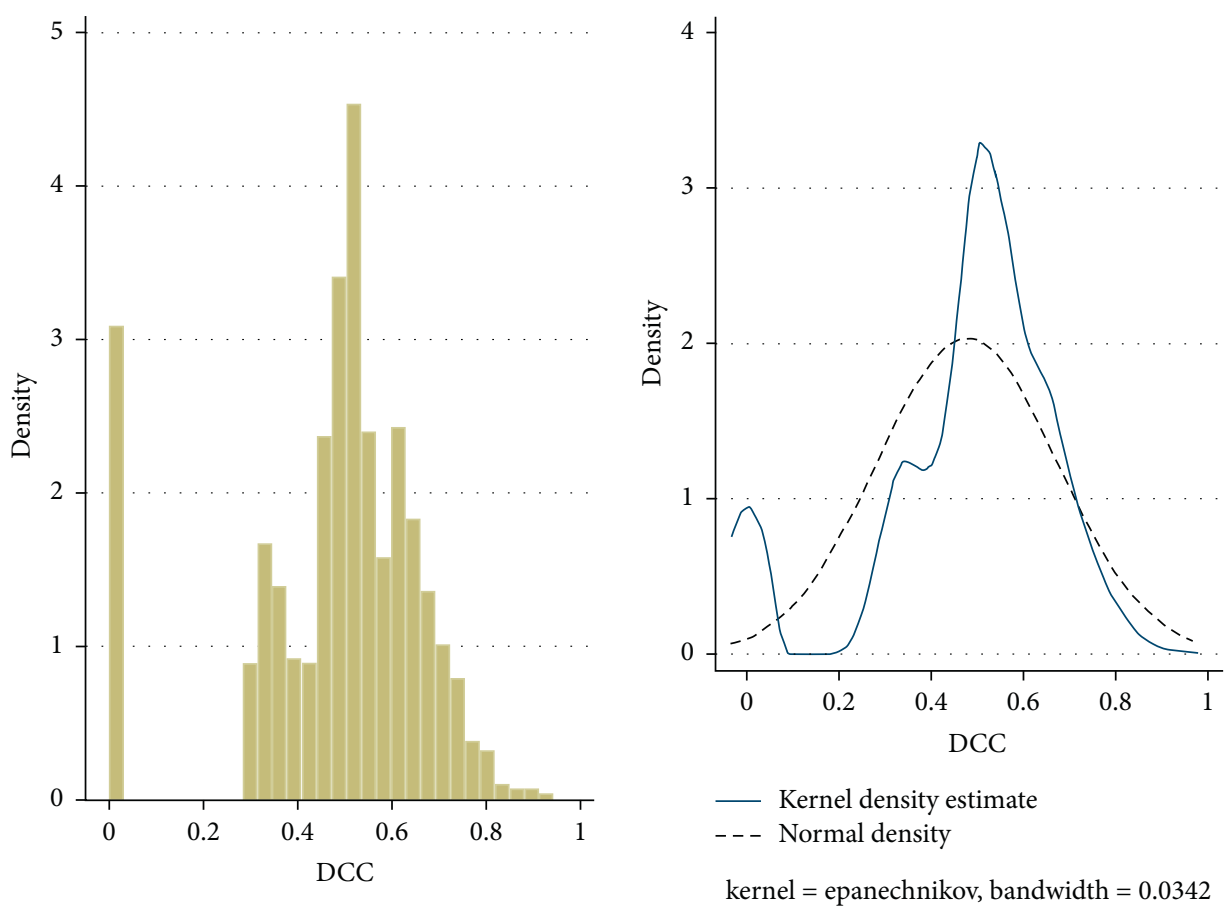

Figure 1: Histogram and kernel density distribution of the DCC.

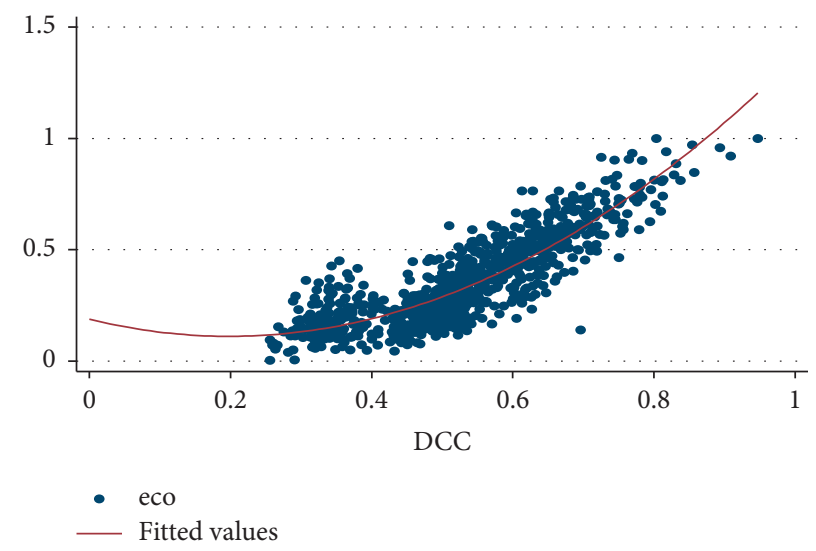

FIGURE 2: Scatter plot of the DCC of cities worldwide.

indicating better-coordinated development of various urban facets. Less developed cities in Asia and Africa, in contrast, have lower DCC. Among the 1,007 sample cities, the DCC of cities in BRICS countries such as China, Russia, and India generally have half of their cities in the latter two tiers, showing bare balance or severe imbalance of development. On the contrary, about half of the cities in G7 countries, such as the United Kingdom, France, and the United States, are in the first two tiers. So, overall, the DCC of cities in G7 countries are generally higher than those of cities of BRICS countries.

3.3. Hierarchical Structure by DCC. In order to conduct a more comprehensive analysis of DCC of cities across the world, this study ranks the city by its economic competitiveness and calculates the average, variance, coefficient of variation, and other statistical data of the cities' coupled coordination within each tier of the ranking. Table 3 shows that the cities ranked the top 20, the top 100, and the 200th have overall better coupling coordination than the cities ranked between the 200the and the 500th cities. The cities ranked below the 500th have imbalance of development. Table 4 shows that the DCC of these sample cities' make up a pyramid-like structure. First, the cities with the highest degrees of coordinated development make up the smallest group, with only 17 cities. Among them, except Sydney, which is an Oceania metropolis, others are the global financial and technology innovation hubs in Europe, America, and Asia. Second, 251 cities are ranked as cities with good coordination. These cities are mostly the financial and technological innovation centers within a region. Third, 


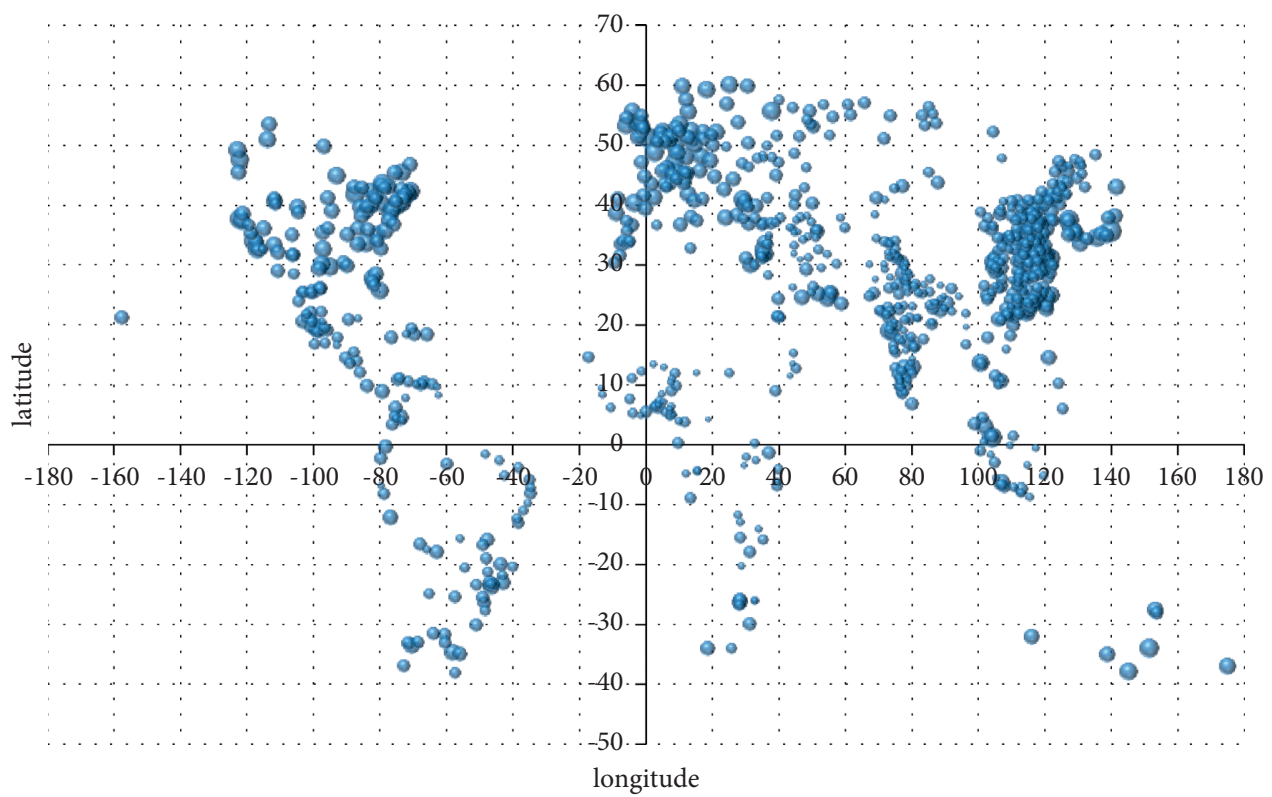

FIgURE 3: Spatial distribution of DCC of the cities around the world.

TABle 3: Data of DCC of cities worldwide.

\begin{tabular}{|c|c|c|c|c|c|c|c|c|}
\hline DCC & Top 20 & Top 100 & 101st-200th & 201st-300th & 301st-500th & 501st-800th & 800th-1007th & All \\
\hline Means & 0.810 & 0.727 & 0.639 & 0.586 & 0.499 & 0.400 & 0.317 & 0.477 \\
\hline Median & 0.808 & 0.723 & 0.641 & 0.601 & 0.530 & 0.473 & 0.354 & 0.513 \\
\hline Categories & $\begin{array}{c}\text { Strong } \\
\text { coordination }\end{array}$ & $\begin{array}{c}\text { Good } \\
\text { coordination }\end{array}$ & $\begin{array}{c}\text { Good } \\
\text { coordination }\end{array}$ & $\begin{array}{c}\text { Limited } \\
\text { coordination }\end{array}$ & $\begin{array}{c}\text { Scanty } \\
\text { coordination }\end{array}$ & $\begin{array}{c}\text { Scanty } \\
\text { coordination }\end{array}$ & $\begin{array}{c}\text { Scanty } \\
\text { coordination }\end{array}$ & $\begin{array}{c}\text { Scanty } \\
\text { coordination }\end{array}$ \\
\hline Levels & Level I & Level II & Level II & Level III & Level IV & Level IV & Level IV & Level IV \\
\hline Variance & 0.004 & 0.005 & 0.003 & 0.008 & 0.019 & 0.032 & 0.032 & 0.038 \\
\hline $\begin{array}{l}\text { Standard } \\
\text { deviation }\end{array}$ & 0.062 & 0.069 & 0.056 & 0.089 & 0.139 & 0.178 & 0.178 & 0.196 \\
\hline $\begin{array}{l}\text { Coefficient } \\
\text { of variation }\end{array}$ & 0.076 & 0.095 & 0.088 & 0.153 & 0.279 & 0.445 & 0.563 & 0.411 \\
\hline
\end{tabular}

TABLE 4: Hierarchy of DCC of cities worldwide.

\begin{tabular}{lcccc}
\hline $\begin{array}{l}\text { Levels } \\
\text { DCC }\end{array}$ & Categories DCC & $\begin{array}{c}\text { Number of the } \\
\text { cities }\end{array}$ & Means & Top 10 cities \\
\hline Level I & $\begin{array}{c}\text { Strong } \\
\text { coordination }\end{array}$ & 16 & 0.839 & New York, tokyo, London, Seoul, Singapore, Beijing, Hong Kong, Shanghai, \\
Sevel II & $\begin{array}{c}\text { Good } \\
\text { coordination }\end{array}$ & 248 & 0.667 & $\begin{array}{c}\text { Osaka, Washington, DC, Atlanta, Houston, Frankfurt, Seattle, Istanbul, } \\
\text { Madrid, Zurich, Philadelphia, etc. }\end{array}$ \\
\hline $\begin{array}{c}\text { Limited } \\
\text { Level III }\end{array}$ & 301 & 0.538 & $\begin{array}{c}\text { Gebze, Leon, Allen, Hermosillo, Palermo, San Juan, Krakow, Hsinchu, Liege } \\
\text { Albuquerque }\end{array}$ \\
\hline Level IV & $\begin{array}{c}\text { Scanty } \\
\text { coordination }\end{array}$ & 442 & 0.317 & $\begin{array}{c}\text { Karaj, Hengshui, Salem, Hebi, Voronezh Benxi, Palembang, Jingdezhen, } \\
\text { Fuyang, Zigong Wait }\end{array}$ \\
\hline
\end{tabular}

306 cities are ranked as cities with limited coordination. These cities have a certain level of coupling coordination and are mostly cities with average levels of economic development of a country, especially those new-economy countries. Fourth, 433 cities are ranked as cities with scanty/insufficient coordination. Most of them are located in Africa, South Asia, and South and East Europe. Table 3 shows the top 10 cities in each ranking category, and most of the cities with remarkable coordination are distributed in China and the
United States. The United States has the most cities among the top 10 in good coordination ranking, while China has the most cities among the top 10 in the limited coordination ranking. The United States has more cities with stronger coupling coordination; China has fewer cities with strong coupling coordination such as Hong Kong, Shanghai, and Shenzhen. Chinese cities are mostly distributed in the middle ranges of the ranking and need improvement in coordinated development. 
3.4. Analysis of the Relative Index of Coupling Coordination. The ratio of the explanatory indicator to the explained indicator is called the relative development index. That is to say, the ratio of each of the nine explanatory indicators, such as financial services, scientific and technological innovation, industrial systems, and human capital, to economic competitiveness index is relative development index. The DCC reflects the degree of coupling and coordinated development between the explanatory indicators of urban economic competitiveness, but it cannot reflect the relative development degree of each explanatory indicator and urban economic competitiveness. To this end, Table 5 and Figure 4 both analyze the relative development of the nine explanatory indicators and economic competitiveness of these cities by continents. Generally speaking, the relative index range between 0.8 and 1.2 indicates a balanced development. Below 0.8 or above 1.2 suggests a lagging development or advanced development.

Table 5 shows that the 1007 sample cities' relative indexes of operation cost, system environment, infrastructure, and living environment are generally higher than 2, indicating more development than urban economic competitiveness; these cities' relative indexes of financial services, technological innovation, and industrial system are generally low, indicating less developed than urban economic competitiveness; their relative index of human resource is around 1.2, suggesting coordinated development with the economic competitiveness. Specifically, the relative indexes of Africa are much higher than the relative development levels of other continents. In Africa, except in the areas of financial services, technological innovation, and the industrial system, the relative development indexes of the human resources, local demand, operation environment, system environment, infrastructure, and living environment are all between 2.7 and 6, way more advanced than the development level of economic competitiveness. In addition, the study found the following: first, in the relatively lower reference indexes of financial services, technological innovation, and industrial systems, sub-Africa and South America see much higher relative development level of financial services than Europe, North America, and Oceania, indicating that the relative development level of financial services in these continents is relatively lagging; Europe, North America, and Oceania have higher level of development in technological innovation than Asia, Africa, and South America; Europe, Oceania, and Africa have higher relative development index of industrial systems than North America, South America, and Asia; it shows that the relative development level of technological innovation in these continents is lagging but higher the world's average. Second, in the mid-range relative development levels of human capital and local demand, Europe, North America, and Oceania see lower indexes than Asia, Africa, and South America, and slightly lower than the world's average, lagging behind the development of economic competitiveness. Third, in the relative higher development levels of operation costs, system environment, infrastructure, and living environment, Asia and Africa have much higher relative indexes than Europe, America, and Oceania. The above conclusions show that the relative development of the nine explanatory indicators of urban economic competitiveness in different continents is different.

\subsection{Regression Analyses of the Factors Affecting Coupling} Coordination of the Cities around the World. In order to verify that the city's DCC is a key factor in urban competitiveness, Tables 6 and 7 are the benchmark regression analysis and factorial regression analysis on the DCC and economic competitiveness.

In Table 6, regression (1) represents the regression results of the economic competitiveness index alone and the DCC; regressions (2)-(5) represent the regression results of the economic competitiveness index and the DCC with additional control variables. Based on the benchmark regression analysis, we found that as the explanatory variables increase, the DCC is consistent with the significance level of other explanatory variables and economic competitiveness. This shows that the regression results are robust. In the regression analysis of (1)-(5), both the economic competitiveness index and the DCC are positively correlated at a $1 \%$ level, indicating a significant positive correlation between the two. The regression coefficient is 0.108 . Table 6 shows that, in addition to the living environment, other indicators such as coupling coordination, financial services, technological innovation, industrial system, human capital, business cost, and business environment are all significantly correlated to economic competitiveness. In addition, the coefficients of each explanatory variable in the regression analysis (5) show that the infrastructure has the strongest impact on economic competitiveness, with a coefficient as high as 0.334 , followed by financial services, technological innovation, and coupling coordination with a coefficient of $0.305,0.305$, and 0.108 , respectively. The least influential are operation cost, industrial system, business environment, and human capital with coefficients $0.252,0.0945,0.0895$, and 0.0703 , respectively. In general, the DCC, financial services, technological innovation, and economic competitiveness are relatively robust and significant variables.

In order to further study the impacts of coupling coordination and other explanatory variables on the economic competitiveness of cities, we conducted a quintile regression analysis as shown in Table 7 . We selected five representative quintiles of $0.1,0.25,0.5,0.75$, and 0.9 , on which the indication and significance levels of the influencing factors are basically the same. However, the coefficient size and significance level display different patterns of change. First, the contribution from coupling coordination and technological innovation to the urban competitiveness is more concentrated near the middle quintiles, indicating that the two factors contribute more to cities with mid-to-upper levels of economic competitiveness. Second, the contribution from financial services to economic competitiveness gradually expands with the increase of urban economic competitiveness, and its significance also gradually increases. Third, the contribution from the industrial system is significant at the 0.1 quintile and 0.75 quintile, but not at other points, indicating that the factor contributes more to the cities with 
TABLE 5: Relative Indexes of coupling coordination of the cities worldwide.

\begin{tabular}{|c|c|c|c|c|c|c|c|c|c|}
\hline \multirow{2}{*}{ Means } & \multicolumn{9}{|c|}{ Relative index } \\
\hline & $\mathrm{FE}$ & $\mathrm{TI}$ & IS & HR & $\mathrm{LD}$ & $\mathrm{CC}$ & SE & In & $\mathrm{LE}$ \\
\hline North America & 0.457 & 0.638 & 0.18 & 0.726 & 1.285 & 1.628 & 1.795 & 1.218 & 1.381 \\
\hline Oceania & 0.432 & 0.704 & 0.387 & 0.67 & 1.111 & 1.125 & 1.521 & 0.953 & 1.194 \\
\hline Africa & 0.906 & 0.34 & 0.322 & 2.709 & 2.841 & 5.002 & 4.678 & 3.582 & 6.408 \\
\hline South America & 0.661 & 0.405 & 0.161 & 1.051 & 1.57 & 1.541 & 1.977 & 1.442 & 1.785 \\
\hline Europe & 0.53 & 0.738 & 0.252 & 0.764 & 1.448 & 1.71 & 2.2 & 1.632 & 2.062 \\
\hline Asia & 0.606 & 0.427 & 0.108 & 1.276 & 1.445 & 2.353 & 2.574 & 2.104 & 2.679 \\
\hline Worldwide & 0.61 & 0.485 & 0.163 & 1.263 & 1.572 & 2.375 & 2.585 & 2.02 & 2.73 \\
\hline
\end{tabular}

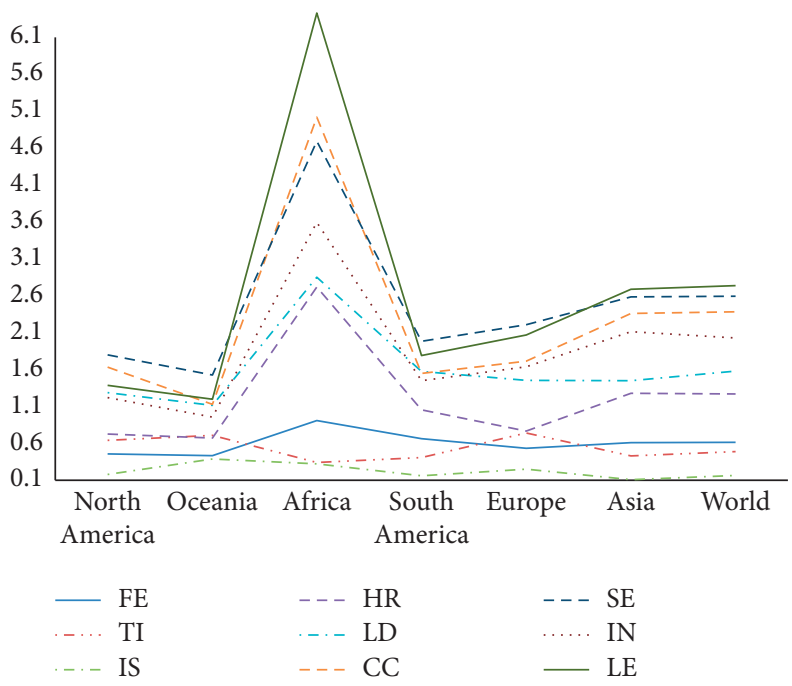

FIGURE 4: Relative indexes of DCC of the cities across the world.

TABLE 6: Benchmark regression analysis on the DCC and economic competitiveness.

\begin{tabular}{|c|c|c|c|c|c|}
\hline & Regression (1) & Regression (2) & Regression (3) & Regression (4) & Regression (5) \\
\hline Variables & $\begin{array}{c}\text { Economic } \\
\text { competitiveness index }\end{array}$ & $\begin{array}{c}\text { Economic } \\
\text { competitiveness index }\end{array}$ & $\begin{array}{c}\text { Economic } \\
\text { competitiveness index }\end{array}$ & $\begin{array}{c}\text { Economic } \\
\text { competitiveness index }\end{array}$ & $\begin{array}{c}\text { Economic } \\
\text { competitiveness index }\end{array}$ \\
\hline DCC & $\begin{array}{c}0.684^{* * *} \\
(30.01) \\
\end{array}$ & $\begin{array}{c}0.177^{* * *} \\
(7.35) \\
\end{array}$ & $\begin{array}{c}0.165^{* * *} \\
(7.59) \\
\end{array}$ & $\begin{array}{c}0.115^{* * *} \\
(5.38) \\
\end{array}$ & $\begin{array}{c}0.108^{* * *} \\
(4.95) \\
\end{array}$ \\
\hline $\mathrm{FE}$ & & $\begin{array}{c}0.508^{* * *} \\
(8.88)\end{array}$ & $\begin{array}{c}0.430^{* * *} \\
(6.03)\end{array}$ & $\begin{array}{c}0.295^{* * *} \\
(4.26)\end{array}$ & $\begin{array}{c}0.305^{* * *} \\
(4.32)\end{array}$ \\
\hline TI & & $\begin{array}{c}0.550^{* * *} \\
(21.46) \\
\end{array}$ & $\begin{array}{c}0.381^{* * *} \\
(14.78) \\
\end{array}$ & $\begin{array}{c}0.303^{* * *} \\
(11.78)\end{array}$ & $\begin{array}{c}0.305^{* * *} \\
(11.71)\end{array}$ \\
\hline IS & & & $\begin{array}{c}0.138^{* * *} \\
(3.33) \\
\end{array}$ & $\begin{array}{c}0.0975^{* *} \\
(2.45)\end{array}$ & $\begin{array}{c}0.0945^{*} \\
(2.36)\end{array}$ \\
\hline HR & & & $\begin{array}{c}0.0837^{* * *} \\
(2.79) \\
\end{array}$ & $\begin{array}{c}0.0706^{* *} \\
(2.44)\end{array}$ & $\begin{array}{c}0.0703^{*} \\
(2.40)\end{array}$ \\
\hline $\mathrm{CC}$ & & & $\begin{array}{c}0.320^{* * *} \\
(15.20) \\
\end{array}$ & $\begin{array}{c}0.252^{* * *} \\
(11.68) \\
\end{array}$ & $\begin{array}{c}0.252^{* * *} \\
(11.61)\end{array}$ \\
\hline SE & & & & $\begin{array}{c}0.0874^{* * *} \\
(3.15) \\
\end{array}$ & $\begin{array}{c}0.0895^{* *} \\
(3.15)\end{array}$ \\
\hline IN & & & & $\begin{array}{c}0.331^{* * *} \\
(9.67) \\
\end{array}$ & $\begin{array}{c}0.334^{* * *} \\
(9.48) \\
\end{array}$ \\
\hline $\mathrm{LE}$ & & & & & $\begin{array}{c}-0.00318 \\
(-0.14)\end{array}$ \\
\hline $\begin{array}{l}\text { Constant } \\
\text { term }\end{array}$ & $\begin{array}{c}0.0190^{*} \\
(1.65) \\
\end{array}$ & $\begin{array}{c}0.0661^{* * *} \\
(6.75) \\
\end{array}$ & $\begin{array}{c}-0.0963^{* * *} \\
(-6.02) \\
\end{array}$ & $\begin{array}{c}-0.208^{* * *} \\
(-10.81) \\
\end{array}$ & $\begin{array}{c}-0.206^{* * *} \\
(-9.86) \\
\end{array}$ \\
\hline Sample size & 1007 & 1007 & 1007 & 1007 & 1007 \\
\hline
\end{tabular}

Note. Brackets indicate t-statistics, ${ }^{*}$ indicates a significance level of $10 \%,{ }^{* *}$ indicates a significance level of $5 \%$, and ${ }^{* * *}$ indicates a significance level of $1 \%$. 
TABLE 7: Quantile regression analysis on economic competitiveness and coupling coordination.

\begin{tabular}{|c|c|c|c|c|c|c|}
\hline & $\begin{array}{l}\text { OIS } \\
\text { eco }\end{array}$ & $\begin{array}{c}0.1 \\
\text { Eco }\end{array}$ & $\begin{array}{l}0.25 \\
\text { eco }\end{array}$ & $\begin{array}{l}0.5 \\
\text { eco }\end{array}$ & $\begin{array}{l}0.75 \\
\text { Eco }\end{array}$ & $\begin{array}{l}0.9 \\
\text { eco }\end{array}$ \\
\hline DCC & $\begin{array}{c}0.115^{* * *} \\
(5.38)\end{array}$ & $\begin{array}{c}0.0758^{* * * *} \\
(2.90)\end{array}$ & $\begin{array}{c}0.0830^{* * *} \\
(2.86)\end{array}$ & $\begin{array}{c}0.0798^{* * *} \\
(2.71)\end{array}$ & $\begin{array}{c}0.146^{* * *} \\
(5.01)\end{array}$ & $\begin{array}{c}0.112^{* * *} \\
(2.67)\end{array}$ \\
\hline $\mathrm{FE}$ & $\begin{array}{c}0.294^{* * *} \\
(4.15)\end{array}$ & $\begin{array}{l}0.137 \\
(1.58) \\
\end{array}$ & $\begin{array}{c}0.182^{*} \\
(1.88) \\
\end{array}$ & $\begin{array}{c}0.356^{* * *} \\
(3.64) \\
\end{array}$ & $\begin{array}{c}0.328^{* * *} \\
(3.39)\end{array}$ & $\begin{array}{c}0.650^{* * *} \\
(4.68)\end{array}$ \\
\hline TI & $\begin{array}{c}0.304^{* * *} \\
(11.70)\end{array}$ & $\begin{array}{c}0.197^{* * * *} \\
(6.16)\end{array}$ & $\begin{array}{c}0.302^{* * * *} \\
(8.52)\end{array}$ & $\begin{array}{c}0.350^{* * * *} \\
(9.73)\end{array}$ & $\begin{array}{c}0.374^{* * * *} \\
(10.51)\end{array}$ & $\begin{array}{c}0.327^{* * *} \\
(6.42)\end{array}$ \\
\hline IS & $\begin{array}{c}0.0977^{* *} \\
(2.45) \\
\end{array}$ & $\begin{array}{c}0.144^{* * *} \\
(2.93) \\
\end{array}$ & $\begin{array}{c}0.0712 \\
(1.31)\end{array}$ & $\begin{array}{c}-0.00391 \\
(-0.07) \\
\end{array}$ & $\begin{array}{c}0.167^{* * *} \\
(3.05) \\
\end{array}$ & $\begin{array}{c}0.0990 \\
(1.26)\end{array}$ \\
\hline Human resources & $\begin{array}{c}0.0704^{* *} \\
(2.41)\end{array}$ & $\begin{array}{c}0.0952^{* * *} \\
(2.65) \\
\end{array}$ & $\begin{array}{c}0.0925^{* *} \\
(2.32) \\
\end{array}$ & $\begin{array}{c}0.0926^{* *} \\
(2.29) \\
\end{array}$ & $\begin{array}{c}0.0281 \\
(0.70)\end{array}$ & $\begin{array}{c}0.00370 \\
(0.06)\end{array}$ \\
\hline Operation cost & $\begin{array}{c}0.252^{* * *} \\
(11.63)\end{array}$ & $\begin{array}{c}0.225^{* * *} \\
(8.46)\end{array}$ & $\begin{array}{c}0.240^{* * *} \\
(8.12)\end{array}$ & $\begin{array}{c}0.247^{* * *} \\
(8.26)\end{array}$ & $\begin{array}{c}0.234^{* * *} \\
(7.89)\end{array}$ & $\begin{array}{c}0.262^{* * *} \\
(6.17)\end{array}$ \\
\hline Business environment & $\begin{array}{c}0.0878^{* * *} \\
(3.09) \\
\end{array}$ & $\begin{array}{c}0.174^{* * *} \\
(4.97)\end{array}$ & $\begin{array}{c}0.131^{* * *} \\
(3.38)\end{array}$ & $\begin{array}{c}0.0576 \\
(1.47) \\
\end{array}$ & $\begin{array}{c}0.0446 \\
(1.15) \\
\end{array}$ & $\begin{array}{c}0.0350 \\
(0.63) \\
\end{array}$ \\
\hline Infrastructure & $\begin{array}{c}0.332^{* * *} \\
(9.45) \\
\end{array}$ & $\begin{array}{c}0.485^{* * *} \\
(11.25) \\
\end{array}$ & $\begin{array}{c}0.452^{* * *} \\
(9.44) \\
\end{array}$ & $\begin{array}{c}0.346^{* * *} \\
(7.13)\end{array}$ & $\begin{array}{c}0.234^{* * *} \\
(4.86) \\
\end{array}$ & $\begin{array}{c}0.310^{* * *} \\
(4.50)\end{array}$ \\
\hline Living environment & $\begin{array}{c}-0.00171 \\
(-0.07)\end{array}$ & $\begin{array}{c}-0.00702 \\
(-0.25)\end{array}$ & $\begin{array}{c}-0.00874 \\
(-0.28)\end{array}$ & $\begin{array}{c}0.0362 \\
(1.14) \\
\end{array}$ & $\begin{array}{c}-0.00542 \\
(-0.17)\end{array}$ & $\begin{array}{r}-0.0863^{*} \\
(-1.92)\end{array}$ \\
\hline _cons & $\begin{array}{c}-0.208^{* * *} \\
(-9.95)\end{array}$ & $\begin{array}{c}-0.371^{* * *} \\
(-14.46) \\
\end{array}$ & $\begin{array}{c}-0.318^{* * *} \\
(-11.16)\end{array}$ & $\begin{array}{c}-0.226^{* * *} \\
(-7.82) \\
\end{array}$ & $\begin{array}{c}-0.0947^{* * *} \\
(-3.31)\end{array}$ & $\begin{array}{c}-0.0504 \\
(-1.23)\end{array}$ \\
\hline $\mathrm{N}$ & 1007 & 1007 & 1007 & 1007 & 1007 & 1007 \\
\hline adj. $R^{2}$ & 0.790 & & & & & \\
\hline
\end{tabular}

higher or lower economic competitiveness than to the cities with median competitiveness. Fourth, the contribution from operating cost to the cities' competitiveness is more even and with little difference at different quintiles. Fifth, the contribution from the business environment is more significant at the lower quintiles than at the mid-to-high quintiles, indicating that the factor has a significantly positive contribution to cities with lower economic competitiveness but a less significant contribution to the cities with higher economic competitiveness. From the above results, we can see that the technological innovation and financial services are the key to enhance urban economic competitiveness.

\section{Conclusion and Discussions}

Urban competitiveness is a huge project; it involves many discipline knowledge, including economy, geography, and urban planning especially, the coordinated development of global urban competitiveness is more systematic and complex, and it is changing dynamically. This article inevitably has shortcomings. The full text establishes a scientific evaluation index system by determining the research logic and technical route. The index system of urban economic competitiveness evaluation is constructed from the perspective of input and output. Generally speaking, there is a certain proportion of the allocation of various elements. Although only one element input will increase the output, with the increase of the input of this element, when the quantity reaches a certain value, the marginal output it brings is in a reduced state, which will cause a waste of resources. Since the output results brought by the input of various elements are also different, unreasonable element allocation will lead to low production efficiency [39, 40], which requires from us to determine different resource element allocation mode according to the productivity of different elements, to maximize realize the coordinated allocation of resources. Therefore, this article also introduces the degree of coupling and coordination (DDC) among multiple explanatory variables. We use empirical analysis to evaluate and analyze the influencing factors of urban economic competitiveness, DCC, and global urban economic competitiveness in the world.

Based on the 1,007 sample cities with a population over 500,000 across the globe, the study got the following conclusion: the global urban economic competitiveness and the degree of coupling and coordination (DCC) are unevenly distributed; the city with higher economic competitiveness rankings has a higher DCC; on the contrary, the opposite is true; the cities with higher DCC are mainly those global cities or metropolis known for financial and technological innovations, such as New York, Tokyo, London, Beijing, and Hong Kong, while cities with lower coupling coordination are mainly in underdeveloped countries in Asia, Africa, and Latin America. This is mainly because those global cities or metropolis have a good social and economic foundation and are in a leading position in financial services, technological innovation, infrastructure construction, and other aspects.

The DCC is pivotal to the cities' economic competitiveness. Improving the coupling and coordination of cities is of great significance to promoting the common prosperity of global cities. In the future, global cities should regard improving the DCC as an important strategic policy. For 
cities in different regions and cities at different stages of development, differentiated policies should be formulated based on relevant factors that affect the improvement of the cities' economic competitiveness.. Overall, they could adopt the principle of "strengthening the strengths to compensate for the weaknesses, laying the foundation and grasping the key" to enhance the competitiveness of global cities. While consolidating existing advantages, they should focus on improving financial service levels, improving technological innovation capabilities, strengthening human resource investment, upgrading urban infrastructure levels, and optimizing the living environment, so that all the people in the world can live a happy life.

In addition, this study uses cross-sectional data, and the evaluation is only based on the current state, while the competitiveness of cities is dynamically changing. In the future, panel data will be used to evaluate the dynamic changes in the competitiveness of world cities. The process is further research work.

\section{Data Availability}

National Academy of Economic Strategy, CASS, and UN Habitat jointly released a "Global Urban Competitiveness Report (2017-2018)." All the data in this article comes from the data of the report 2017. Ownership of the data does not belong to us. Because the data is obtained for a fee. So, it cannot be provided.

\section{Conflicts of Interest}

The authors declare that they have no conflicts of interest.

\section{References}

[1] H. Haken, "Circuits \& devices magazine," IEEE, vol. 28, no. 9, pp. 412-414, 1997.

[2] L. V. Bertalanffy, Basics, Development and Application of General System Theory, Tsinghua University Press, Beijing, CHN, 1987.

[3] G. Bi, Q. Yang, and S. Liu, "Coupling and coordinative development of China's provincial ecological civilization construction and urbanization," Economic Geography, vol. 37, no. 01, pp. 50-58, 2017.

[4] C. liao, "The quantitative evaluation and classification system of the coordinated development of environment and economy: taking the urban agglomeration of the pearl river delta as an example," Tropical Geography, vol. 2, pp. 76-82, 1999.

[5] D. Wu, L. Cao, and L. Chen, Principles and Application of Synergetics, Huazhong University of Science and Technology Press, Wuhan, CHN, 1990.

[6] X. Liu and P. Ni, "Analysis of coupling and coordination degree of competitiveness of Chinese large and medium cities," Journal of Hebei University of Economics and Business, vol. 40, no. 2, pp. 57-64, 2019.

[7] M. Storper, "The city: centre of economic reflexivity," Service Industries Journal, vol. 17, no. 1, pp. 1-27, 1997.

[8] J. Shen, "Urban competitiveness and urban governance in the globalizing world," Asian Geographer, vol. 23, no. 1-2, pp. 19-36, 2004.
[9] R. Martin and J. Simmie, "Path dependence and local innovation systems in city-regions," Innovation, vol. 10, no. 2-3, pp. 183-196, 2008.

[10] E. J. Malecki, "Hard and soft networks for urban competitiveness," Urban Studies, vol. 39, no. 5, pp. 929-945, 2002.

[11] M. Boddy, "Geographical economics and urban competitiveness: a critique," Urban Studies, vol. 36, no. 5-6, pp. 811-842, 1999.

[12] W. F. Lever, "Competition within the European urban system," Urban Studies, vol. 30, no. 6, pp. 935-948, 1993.

[13] W. F. Lever, "Competitive cities in Europe," Urban Studies, vol. 36, no. 5, pp. 1029-1044, 1999.

[14] W. F. Lever, "The knowledge base and the competitive city," in Urban Competitiveness: Policies for Dynamic Cities, I. Begg, Ed., Bristol University Press, pp. 11-32, Bristol, UK, 2002.

[15] J. Haughton and V. Slobodyanyuk, State Competitiveness Report 2001, Beacon Hill Institute, Boston, 2001, http://www. beaconhill.org/CompetitivenessHomePage.html.

[16] D. G. Tuerck, J. Haughton, F. Conte et al., State Competitiveness Report 2007, Beacon Hill Institute, Boston, 2007, http://www.beaconhill.org/CompetitivenessHomePage. html.

[17] M. Kitson, R. Martin, and P. Tyler, "Regional competitiveness: an elusive yet key concept?” Regional Studies, vol. 38, no. 9, pp. 991-999, 2004

[18] P. K. Kresl, Planning Cities for the Future: The Successes and Failures of Urban Economic Strategies in Europe, Edward Elgar Publishing, UK, 2007.

[19] B. Gardiner, R. Martin, and P. Tyler, "Head," Regional Studies, vol. 38, no. 9, pp. 1045-1067, 2004.

[20] S. Iyer, M. Kitson, and B. Toh, "Social capital, economic growth and regional development," Regional Studies, vol. 39, no. 8, pp. 1015-1040, 2005.

[21] R. Camagni, R. Capello, and P. Nijkamp, “Towards sustainable city policy: an economy-environment technology nexus: an economy-environment technology nexus," Ecological Economics, vol. 24, no. 1, pp. 103-118, 1998.

[22] J. Jacobs, The Economy of Cities, Vintage, New York, USA, 1969.

[23] I. Begg, "Cities and competitiveness," Urban Studies, vol. 36, no. 5-6, pp. 795-809, 1999.

[24] S. Hao and P. Ni, "Research on the competitiveness of Chinese cities-taking several cities as cases," Economic Science, vol. 20, no. 3, pp. 50-56, 1998.

[25] P. Ni, "Analysis paradigm and conceptual framework of Chinese urban competitiveness," Economic Dynamics, vol. 6, pp. 14-18, 2001.

[26] I. Turok, "Cities, regions, and competitiveness," Regional Studies, vol. 38, no. 9, pp. 1069-1083, 2004.

[27] W. J. Steinle, "Regional competitiveness and the single market," Regional Studies, vol. 26, no. 4, pp. 307-318, 1992.

[28] P. J. Taylor, P. Ni, B. Derudder, M. Hoyler, J. Huang, and F. Witlox, Catalano G. Global Urban Analysis: A Survey of Cities in Globalization, Routledge, London, UK, 2012.

[29] J. Bruneckiene, A. Guzavicius, and R. Cincikaite, "Measurement of urban competitiveness in Lithuania[J]," Engineering Economics, vol. 21, no. 5, pp. 493-508, 2010.

[30] R. J. Rogerson, "Quality of life and city competitiveness," Urban Studies, vol. 36, no. 5, pp. 969-985, 1999.

[31] E. D’Arcy and G. Keogh, “The property market and urban competitiveness: a review," Urban Studies, vol. 36, no. 5-6, pp. 917-928, 1999.

[32] M. M. Kritz and R. E. Bilsborrow, "Migration, urbanization, and development: new directions and issues," Population and Development Review, vol. 24, no. 3, pp. 639-642, 1998. 
[33] B. Gardiner, R. Martin, P. Sunley, and P. Tyler, "Spatially unbalanced growth in the British economy," Journal of Economic Geography, vol. 13, no. 6, pp. 889-928, 2013.

[34] P. Ni and P. K. Kresl, Global City Competitiveness Report: Competitiveness Challenges the World City System, Social Science Literature Press, Beijing, CHN, 2006.

[35] P. Ni, China City Competitiveness Report NO. 17, Social Science Academic Press, Beijing, CHN, 2017.

[36] M. Porter, "Competitive advantage of nations," Harvard Business Review, vol. 2, 1990.

[37] T. Berger, "Concepts of national competitiveness," Journal of International Business and Economy, vol. 9, no. 1, pp. 91-112, 2008.

[38] P. Ni, B. Zhao, and H. Wei, "Competitive index construction and factor Analysis: based on a sample of 500 global typical cities," Urban Development Studies, vol. 20, no. 6, pp. 72-79, 2013.

[39] L. X. Yang, "A Re-examination of the causes of China's overcapacity from the perspective of all factors: based on the decomposition research of resource allocation and factor production efficiency," Social Sciences in Guangdong, vol. 187, no. 5, pp. 14-22, 2017.

[40] C. R. Sun, Q. Qin, and S. Wang, "Does centrality of cities promote the upgrading of urban export structures?: evidence from Chinese cities and urban groups," World Economy Studies, vol. 323, no. 1, pp. 17-31, 2021. 